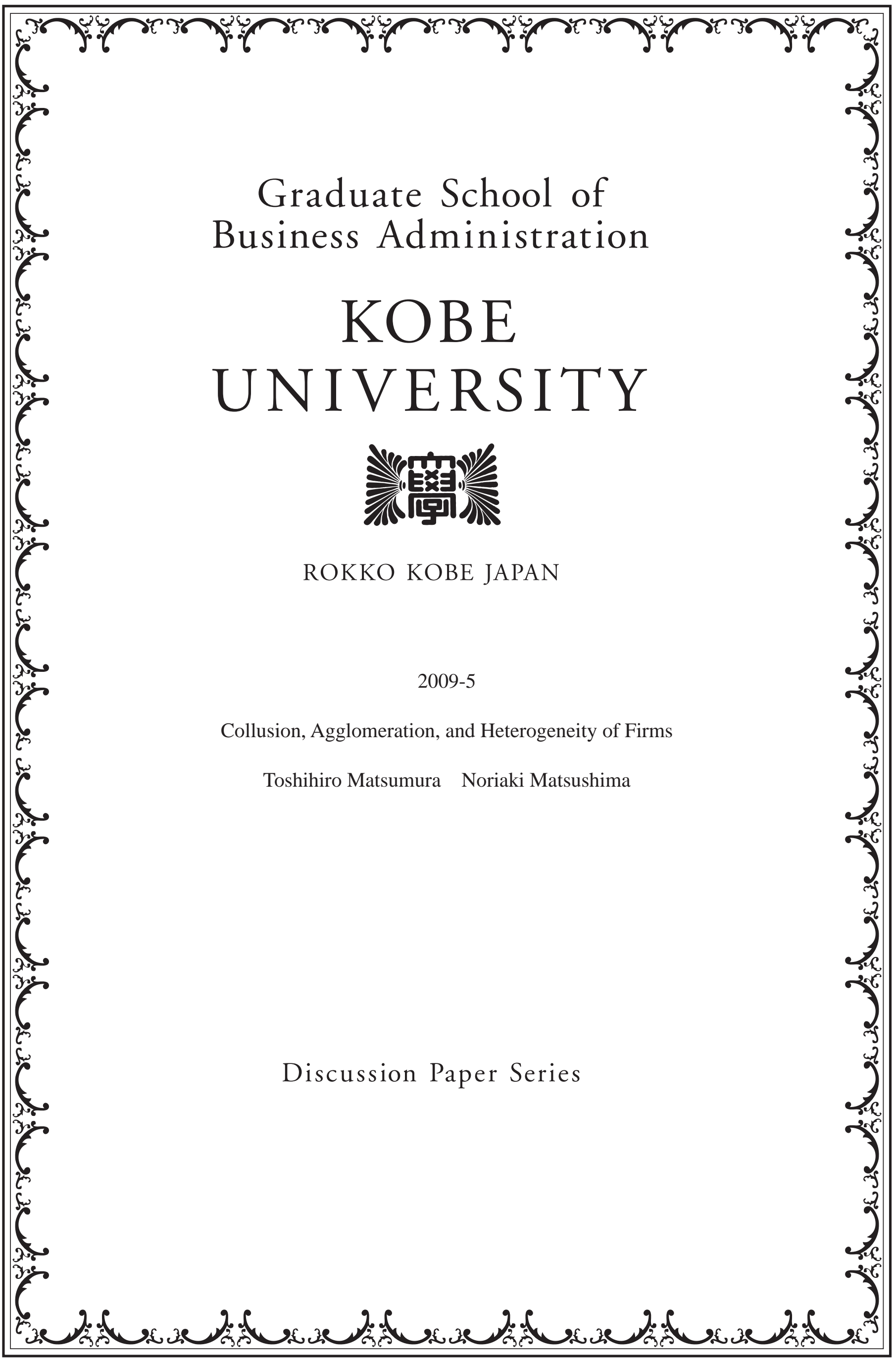




\title{
Collusion, Agglomeration, and Heterogeneity of Firms
}

\author{
Toshihiro Matsumura \\ Institute of Social Science, University of Tokyo \\ and \\ Noriaki Matsushima* \\ Graduate School of Business Administration, Kobe University
}

February 18, 2009

\begin{abstract}
Friedman and Thisse (RAND Journal of Economics, 1993) show that spatial agglomeration appears in a standard two-stage location price model if the symmetric firms can collude in prices. We introduce a cost difference between two firms. We show that agglomeration never appears in a collusive equilibrium even when the cost difference between the firms is sufficiently small.
\end{abstract}

JEL classification numbers: L13, R32, L41

Key words: cost asymmetry, spatial agglomeration, collusion

${ }^{*}$ Corresponding author: Noriaki Matsushima, Graduate School of Business Administration, Kobe University, Rokkodai 2-1, Nada, Kobe, Hyogo 657-8501, Japan. Phone: +81-78-803-6981, Fax: +81-78-8036977, E-mail: nmatsush@kobe-u.ac.jp 


\section{Introduction}

Since the seminal work of Hotelling [6], the model of spatial competition has been seen by many subsequent researchers as an attractive framework for analyzing product differentiation. The major advantage of this approach is that it allows an explicit analysis of product selection. Of particular interest is the equilibrium pattern of product locations and the degree of product differentiation. The original finding of Hotelling [6] is that firms produce similar products (minimum differentiation). d'Aspremont et al. [2] consider twostage location-price games on the Hotelling line. They show that products are maximally differentiated when transport costs are quadratic. The firms in their study never choose minimal differentiation so as to avoid cutthroat competition in the price competition stage.

Friedman and Thisse [4] investigate a collusion in the price-setting stage. They assume that firms choose their locations non-cooperatively and then divide collusive profits according to their relative profits at status quo. They show that firms agglomerate at the central point, restoring minimal differentiation. The logic behind the result is as follows. Suppose that firm 1 (firm 2) locates initially at the left (right) side in the city, and not at the central point. Now, suppose that firm 1 moves to the central point. First, consider the competitive phase. The move by firm 1 increases the demand for it (as is discussed by Hotelling [6]) and, at the same time, accelerates competition, thereby resulting in lower prices (as is discussed by d'Aspremont et al. [2]). The accelerated competition as a result of the move by firm 1 reduces the profits of firm 2 more significantly: while both effects discussed above diminish the profits of firm 2, only the latter effect reduces the profits of firm 1. Next, consider the collusive phase. Since the accelerated competition reduces the profits of firm 2 at status quo more significantly than those of firm 1, the move by firm 1 improves its bargaining position (by increasing its relative profits). Thus, when they can collude, firm 1 has a strong incentive to locate close to its rival; this results in central agglomeration. ${ }^{1}$ Jehiel [7] also investigates this problem and shows that central

\footnotetext{
${ }^{1}$ There are many other papers that discuss central agglomeration without collusion. See, de Palma et al. [3], Hamilton et al. [5], Anderson and Neven [1], and Mai and Peng [8].
} 
agglomeration appears under Nash bargaining without monetary transfer (side payment). Rath and Zhao [10] extend these studies to more general bargaining games and show that central agglomeration is always an equilibrium outcome, though it may not be the unique equilibrium outcome. ${ }^{2}$

We introduce a cost asymmetry between two firms. We find that even a slight difference in cost has a drastic impact on the result: under a general allocation rule of collusive profits, firms never agglomerate.

The paper is organized as follows. Section 2 formulates a basic model where monetary transfer (side payment) is possible. Section 3 presents our non-agglomeration result. Section 4 investigates the model without monetary transfer and shows a similar nonagglomeration result. Section 5 concludes the paper.

\section{The Model}

In sections $2-3$, we assume that monetary transfer (side payment) between two firms is possible and firms split monopoly profits directly. In section 4, we investigate a nontransferable case, where firms split their market shares through a coordination of their prices.

We formulate a duopoly model with a linear city a la Hotelling. The linear city of length 1 lies on the abscissa of a line and consumers are uniformly distributed with density 1 along this interval. Suppose that firm $i(i=1,2)$ is located at point $x_{i} \in[0,1]$. A consumer living at $y \in[0,1]$ incurs a transport cost of $t\left(x_{i}-y\right)^{2}$ when (s)he purchases the product from firm $i$. The consumers have unit demands, i.e., each consumes one or zero unit of the product. Each consumer derives a surplus from consumption (gross of price and transport costs) equal to $s$. We assume that $s$ is so large that the market is fully covered. ${ }^{3}$ Firms 1 and 2 produce the same physical product. Each firm maximizes its own profits. The unit cost of the product for each firm is $c_{i}$, which is given exogenously. Without loss of

\footnotetext{
${ }^{2}$ They show that under the egalitarian solution and the Kalai-Smorodinsky solution, multiple equilibria, including the case of central agglomeration, exist.

${ }^{3}$ A sufficient condition is $s>3 t+c$.
} 
generality, we assume that firm 1's marginal cost is zero and firm 2's is $c \geq 0$. We assume that $c \leq t$.

The game runs as follows. In the first stage, each firm $i$ chooses its location $x_{i} \in[0,1]$ simultaneously. In the second stage, each firm $i$ chooses its price $p_{i} \in\left[c_{i}, \infty\right)$ simultaneously. The firms collude in the second stage, while they choose their locations non-cooperatively in the first stage. ${ }^{4}$

The firms split the collusive profit through bargaining at the beginning of the second stage. Firm 1's profit is given by $\Pi_{1}^{B}\left(\Pi^{M}, \Pi_{1}^{C}, \Pi_{2}^{C}\right)$ and firm 2's profit is $\Pi^{M}-\Pi_{1}^{B}$, where $\Pi^{M}$ is the collusive profit (maximized joint profit) and $\Pi_{i}^{C}$ is the competitive profit (profit when firms do not collude in prices) of firm $i$. We make the following assumption on the payoff function through bargaining.

\section{Assumption 1}

$$
1 \geq \frac{\partial \Pi_{1}^{B}}{\partial \Pi^{M}} \geq 0, \quad \frac{\partial \Pi_{1}^{B}}{\partial \Pi_{1}^{C}}>0, \quad \frac{\partial \Pi_{1}^{B}}{\partial \Pi_{2}^{C}}<0 .
$$

The first part in Assumption 1 implies that an increase in joint profit benefits all firms; the second and third inequalities imply that an increase in its own profits at the threat point increases its profits through bargaining.

\section{Results}

Friedman and Thisse [4] present an attractive explanation of minimum differentiation: firms dare to choose minimum differentiation to improve their bargaining position. The following proposition indicates that this holds only if $c=0$ (no cost differentiation).

Proposition 1 Under Assumption 1, minimal differentiation constitutes an equilibrium only if $c=0$.

Proof Suppose that $c>0$ and $x_{1}=x_{2}$ in equilibrium. Without loss of generality we

\footnotetext{
${ }^{4}$ We implicitly consider the following repeated price-setting game. The firms simultaneously and noncooperatively select their locations at the beginning of time; once chosen, the locations are fixed, but the firms will select their prices in each of the subsequent periods. In other words, the firms collusively arrange a trigger strategy equilibrium in prices, and select their locations knowing that the trigger strategy price equilibrium will ensue.
} 
assume that $x_{1} \leq 1 / 2$. In the equilibrium, at the competitive stage (at the threat point), firm 2 sets $p_{2}=c$, and firm 1 undercuts firm 2's price and obtains the whole market. As a result, $\Pi_{1}^{C}=c$ and $\Pi_{2}^{C}=0$.

Suppose that firm 2 deviates from the equilibrium location $x_{1}=x_{2}$ and chooses $x_{2}=$ $x_{1}+\varepsilon$, where $\varepsilon$ is positive and sufficiently small. This relocation never reduces $\Pi^{M}$ because production efficiency is improved by the differentiation. After the deviation, $\Pi_{1}^{C}=c-\left(t\left(1-x_{1}\right)^{2}-t\left(1-x_{1}-\varepsilon\right)^{2}=c-t \varepsilon\left(2-2 x_{1}-\varepsilon\right)<c\right.$ and $\Pi_{2}^{C}=0 .{ }^{5}$ Thus, the deviation improves firm 2's payoff, a contradiction.

Q.E.D.

When two firms are symmetric, both firms' profits at the threat point (competitive stage) are minimized when $x_{1}=x_{2}$. Thus, both firms choose agglomeration in order to minimize the rival's profits. When firm 2 is inferior to firm 1, however, firm 1's profits are locally maximized when $x_{1}=x_{2}$ and firm 2's profits are independent of its location as long as $\left|x_{1}-x_{2}\right|$ is sufficiently small. ${ }^{6}$ Thus, firm 2 has an incentive to avoid agglomeration. This yields our discontinuous result with respect to $c$ (the cost difference between two firms).

\section{Nontransferable profits}

In sections $2-3$, we assume that monopoly profit is transferable between two firms. Suppose that $x_{1}=x_{2}$. Then, the joint profit is maximized by the monopoly of firm 1 , and monetary transfer from firm 1 to firm 2 is made. In this section, we consider a situation where monetary transfer is impossible (no side payment).

At the beginning of the second stage, firms coordinate their prices through bargaining. The profits of firm 1 and firm 2 at the collusive stage are given by $\Pi_{1}^{B N}\left(F, \Pi_{1}^{C}, \Pi_{2}^{C}\right)$ and $\Pi_{2}^{B N}\left(F, \Pi_{2}^{C}, \Pi_{1}^{C}\right)$, respectively, where $F$ is a feasible set of their profits.

We make the following three assumptions on the payoff function through bargaining.

\footnotetext{
${ }^{5}$ See Result 1 in Matsumura and Matsushima [9]. It shows that firm 1 obtains the whole market if and only if $c \geq t\left(x_{2}-x_{1}\right)\left(4-x_{1}-x_{2}\right)$.

${ }^{6}$ This statement means that the profit of firm 2 is zero if $x_{1}$ and $x_{2}$ satisfy the following inequality, $c \geq t\left(x_{2}-x_{1}\right)\left(4-x_{1}-x_{2}\right)$. See Matsumura and Matsushima [9].
} 
Assumption 2 The bargaining yields an efficient outcome, i.e., $\left(\Pi_{1}^{B N}\left(F, \Pi_{1}^{C}, \Pi_{2}^{C}\right), \Pi_{2}^{B N}\left(F, \Pi_{2}^{C}, \Pi_{1}^{C}\right)\right)$ lies on the frontier of the feasible set.

\section{Assumption 3}

$$
\frac{\partial \Pi_{i}^{B N}}{\partial \Pi_{i}^{C}}>0, \quad \frac{\partial \Pi_{i}^{B N}}{\partial \Pi_{j}^{C}}<0 \quad(i=1,2, i \neq j) .
$$

Assumption 4 For a positive constant $\delta$, if $\left(\Pi_{1}^{B N}\left(F, \Pi_{1}^{C}, \Pi_{2}^{C}\right), \Pi_{2}^{B N}\left(F, \Pi_{2}^{C}, \Pi_{1}^{C}\right)+\delta\right) \in F^{\prime}$, then $\Pi_{2}^{B N}\left(F^{\prime}, \Pi_{2}^{C}, \Pi_{1}^{C}\right) \geq \Pi_{2}^{B N}\left(F, \Pi_{2}^{C}, \Pi_{1}^{C}\right)$.

Assumption 4 implies that if the feasible set is enlarged and firm 2 has an opportunity to increase its payoff without reducing firm 1's profits, firm 2's profits through bargaining never decrease by the change of the feasible set.

Suppose that $x_{1}<x_{2}$. Firm 1 obtains the consumers living at $x \in[0, \tilde{x}]$ and firm 2 obtains consumers living at $x \in(\tilde{x}, 1]$, where $\tilde{x}$ is given by

$$
\tilde{x}=\max \left\{\min \left\{\frac{x_{1}+x_{2}}{2}+\frac{p_{2}-p_{1}}{2 t\left(x_{2}-x_{1}\right)}, 0\right\}, 1\right\} .
$$

Henceforth, at the collusive stage we assume that $\tilde{x} \in(0,1)$, i.e., both firms obtain positive profits at the collusive stage. Let $p_{i}^{E}$ be the equilibrium price at the collusive stage. Then, because the market is fully covered, both $p_{1}^{E} \leq s-t\left(x_{1}\right)^{2}$ and $p_{2}^{E} \leq s-t\left(1-x_{2}\right)^{2}$ are satisfied. ${ }^{7}$ At least one of the two inequalities stated above must be satisfied with strict equality at the collusive stage; otherwise, firms could raise both $p_{1}^{E}$ and $p_{2}^{E}$ without changing the demand for either firm. If the two firms agglomerate at a point $\left(x_{1}=x_{2}\right)$, they set the highest price that induces all consumers to buy (the market is fully covered), and then coordinate their market shares through bargaining (if their prices are different, the firm setting the lower price appropriates the entire demand).

We then suppose that $x_{1}^{E}=x_{2}^{E}$ in equilibrium and derive a contradiction. When $x_{1}^{E}=x_{2}^{E}$, we assume without loss of generality that firm 2 locates just to the right-side of firm 1. Then, firm 2 obtains the consumers living at $x \in(\tilde{x}, 1]$ at the collusive stage. If firm 2 deviates from the equilibrium location and chooses $x_{2}^{\prime}>x_{2}^{E}$, then firm 2 obtains the consumers living at $x \in\left[x^{\prime}, 1\right]$ at the collusive stage. If firm 2 deviates from the

\footnotetext{
${ }^{7}$ Full coverage at the collusive stage holds since we assume that $s$ is sufficiently large.
} 
equilibrium location and chooses $x_{2}^{\prime \prime}<x_{2}^{E}$, then firm 2 obtains the consumers living at $x \in\left[0, x^{\prime \prime}\right]$ at the collusive stage (note that firm 2 now locates to the left-side of firm 1 ). Given the locations of the two firms, $\tilde{x}, x^{\prime}$ and $x^{\prime \prime}$ are determined indirectly through price bargaining.

We now make the final assumption.

Assumption 5 If $c>0$ and $x_{1}^{E}=x_{2}^{E}$, then $\tilde{x}>1 / 2$.

Suppose that Assumption 5 is not satisfied $\left(\tilde{x} \leq 1 / 2\right.$ when $c>0$ and $\left.x_{1}^{E}=x_{2}^{E}\right)$. Then, both firms 1 and 2 obtain the same market share or firm 2 obtains a larger market share, despite firm 2's profits being smaller at the threat point. We believe that it is natural to assume that the superior firm (firm 1) obtains the larger market share. The Nash bargaining solution discussed by Jehiel [7] satisfies this assumptions.

Proposition 2 Under Assumptions 2-5, minimum differentiation constitutes an equilibrium only if $c=0$.

Proof Suppose that $c>0$ and $x_{1}^{E}=x_{2}^{E}$. Before the deviation, firm 2 obtains the consumers living at $x \in[\tilde{x}, 1]$ at the collusive stage. We then show that firm 2 can improve its payoff by a deviation. We consider three cases: (i) $x_{2}^{E}<\tilde{x}$; (ii) $\tilde{x}<x_{2}^{E}$; (iii) $\tilde{x}=x_{2}^{E}$.

In the proof of Proposition 1, we show that the deviation reduces $\Pi_{1}^{C}$ without changing $\Pi_{2}^{C}$ if firm 2 deviates from the equilibrium strategy and chooses $x_{2}^{\prime} \neq x_{2}^{E}$ where $x_{2}^{\prime}$ is sufficiently close to $x_{2}^{E} \cdot 8$

Let $F^{A}$ and $F^{B}$ respectively be the feasible sets of the collusive payoffs of firms 1 and 2 after and before the deviation.

First, we suppose that $x_{2}^{E}<\tilde{x}$. Firm 2 now deviates and chooses $x_{2}^{\prime}>x_{2}^{E}$. After the deviation, at the collusive stage, firm 2 can increase $p_{2}$ by $t\left(x_{2}^{E}-\tilde{x}\right)^{2}-t\left(x_{2}^{\prime}-\tilde{x}\right)^{2}$ without

\footnotetext{
${ }^{8}$ This statement means that $x_{1}^{E}=x_{2}^{E}$ and $x_{2}^{\prime}$ satisfy the following inequality, $c \geq t\left(x_{2}^{\prime}-x_{2}^{E}\right)\left(4-x_{1}^{E}-x_{2}^{\prime}\right)$.
} 
changing its demand given $p_{1}^{E} \cdot{ }^{9}$ Thus, $\Pi_{1}^{B N}\left(F^{B}, ..\right), \Pi_{2}^{B N}\left(F^{B}, ..\right)+t\left(\left(x_{2}^{E}-\tilde{x}\right)^{2}-\left(x_{2}^{\prime}-\right.\right.$ $\left.\tilde{x})^{2}\right)(1-\tilde{x}) \in F^{A}$. This implies that the deviation improves firm 2's payoff (Assumption 4), a contradiction. Note that we have already shown that the deviation improves the threat point of firm 2 (Proof of Proposition 1).

Second, we suppose that $\tilde{x}<x_{2}^{E}$. This is possible only if $x_{1}^{E}=x_{2}^{E}>1 / 2$, because firm 1 has to secure more than half of the market demand (Assumption 5). Firm 2 now deviates and chooses $x_{2}^{\prime}<x_{2}^{E}$. After the deviation, firm 2 obtains the consumers living at $x \in\left[0, x^{\prime}\right]$ at the collusive stage. Let $p_{i}^{E}$ be the equilibrium price of firm $i$ at the collusive stage before the deviation. At the collusive stage, firm 2 can set $x^{\prime}=1-\tilde{x}$ by setting $p_{2}^{\prime}=p_{2}^{E}+t\left(x_{1}^{E}-x^{\prime}\right)^{2}-t\left(x_{2}^{\prime}-x^{\prime}\right)^{2}$ given $p_{1}^{E} .^{10}$ This again implies that the deviation improves firm 2's payoff (Assumption 4), a contradiction.

Finally, we suppose that $\tilde{x}=x_{2}^{E}$. This is possible only if $x_{1}^{E}=x_{2}^{E}>1 / 2$ because firm 1 has to secure more than half of the market (Assumption 5). Firm 2 now deviates and chooses $x_{2}^{\prime}<x_{2}^{E}$. After the deviation, firm 2 obtains the consumers living at $x \in\left[0, x^{\prime}\right]$ at the collusive stage. Before the deviation, since the market is fully covered, and $x_{1}^{E}>1 / 2$, $p_{1}^{E}=s-t\left(x_{1}^{E}\right)^{2}$. Note that the constraint $p_{2}^{E} \leq s-t\left(1-x_{2}^{E}\right)^{2}$ is not binding since $x_{2}^{E}>1 / 2$. After the deviation, at the collusive stage, both firms can raise prices by $t\left(x_{1}^{E}\right)^{2}-t\left(x^{\prime}\right)^{2}$ since the constraint $p_{1}^{E} \leq s-t\left(x_{1}^{E}\right)^{2}$ is replaced with $p_{2}^{E} \leq s-t\left(x_{2}^{\prime}\right)^{2}$ and hence relaxed. On the other hand, the constraint $p_{2}^{E} \leq s-t\left(1-x_{2}^{E}\right)^{2}$ is replaced with $p_{1}^{E} \leq s-t\left(1-x_{1}^{E}\right)^{2}$ and thereby strengthened. However, $p_{1}^{E} \leq s-t\left(1-x_{1}^{E}\right)^{2}$ is not binding since $x_{1}^{E}>1 / 2$ (See Figure 1). The deviation does not affect the collusive price $p_{2}^{E}$. Thus, the deviation enlarges the feasible set. This again implies that the deviation improves firm 2's payoff

${ }^{9}$ This is derived by the following equation

$$
1-\tilde{x}=1-\left(\frac{x_{1}^{E}+x_{2}^{\prime}}{2}+\frac{p_{2}^{\prime}-p_{1}^{E}}{2 t\left(x_{2}^{\prime}-x_{1}^{E}\right)}\right) .
$$

As mentioned earlier, when $x_{1}^{E}=x_{2}^{E}$, firms coordinate their market shares through bargaining.

${ }^{10} p_{2}^{\prime}$ is derived by the following equation

$$
x^{\prime}=\frac{x_{1}^{E}+x_{2}^{\prime}}{2}+\frac{p_{1}^{E}-p_{2}^{\prime}}{2 t\left(x_{1}^{E}-x_{2}^{\prime}\right)} .
$$

As mentioned earlier, when $x_{1}^{E}=x_{2}^{E}$, they coordinate their market shares through bargaining. 
(Assumption 4), a contradiction.

Q.E.D.

Propositions 1 and 2 imply that under a broad class of bargaining situations, location then collusive pricing models do not yield agglomeration when two firms are asymmetric. ${ }^{11}$ This is because a cost difference results in a conflict of interests between two firms at the competitive stage. The superior firm's profit is locally maximized around an agglomeration point, while the inferior firm's profit is independent of locations around the agglomeration point. This is why the inferior firm has a strong incentive to avoid minimum differentiation.

\section{Concluding Remarks}

In this paper we discuss how cost asymmetry between firms affects the possibility of central agglomeration in location then collusion models. In contrast to the existing results under cost symmetry, firms never agglomerate under conditions of even slight cost asymmetry. Cost asymmetry creates a conflict of interest between firms. The superior firm's profits are locally maximized at the agglomeration, while it is locally minimized without cost asymmetry. The inferior firm, therefore, has a strong incentive to avoid agglomeration so as to reduce the rival's status quo profit under cost asymmetry. This yields our contrasting results. We believe that this result holds true for more than two firms and other specifications of space, such as a circular-city model.

Our result holds for cases where the superior firm chooses its location first and the inferior firm then selects its location on the basis of the former's choice. If the location choice is inversed, our result does not hold and agglomeration equilibrium appears. We believe, however, that the superior firm naturally moves first. The superior firm, in all likelihood, is an innovator, while the inferior firm is quite possibly an imitator. In such a situation, it is natural that the innovator chooses its product position first.

[2009.2.17, 909]

\footnotetext{
11 The Kalai-Smorodinsky solution does not satisfy Assumption 4. We can, however, show that under this solution agglomeration does not appear when $c \neq 0$. The proof is almost the same as the current proof of proposition 2 . When $x_{1}=x_{2} \leq 1 / 2$, firm 2 can improve its payoff with the deviation $x_{2}^{\prime}=x_{1}+\varepsilon$; when $x_{1}=x_{2}>1 / 2$, firm 2 can improve its payoff with the deviation $x_{2}^{\prime}=x_{1}-\varepsilon$.
} 


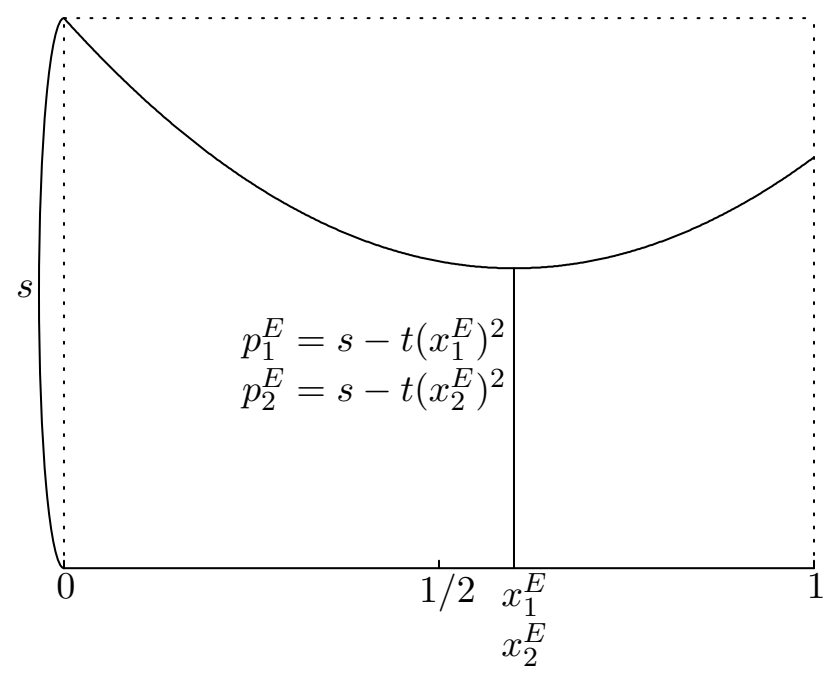

Figure 1: $p_{1}^{E} \leq s-t\left(1-x_{1}^{E}\right)^{2}$ is not binding. 


\section{References}

[1] S. P. Anderson and D. J. Neven, Cournot competition yields spatial agglomeration. International Economic Review 32(4) (1991) 793-808.

[2] C. d'Aspremont, J.-J. Gabszewicz, and J.-F. Thisse, On Hotelling's stability in competition. Econometrica 47(5) (1979) 1145-1150.

[3] A. De Palma, V. Ginsburgh, Y. Y. Papageorgiou, and J.-F. Thisse, The principle of minimum differentiation holds under sufficient heterogeneity. Econometrica 53(4) (1985) $767-781$.

[4] J. W. Friedman and J.-F. Thisse, Partial collusion fosters minimum product differentiation. RAND Journal of Economics 24(4) (1993) 631-645.

[5] J. H. Hamilton, J.-F. Thisse, and A. Weskamp, Spatial discrimination: Bertrand vs. Cournot in a model of location choice. Regional Science and Urban Economics 19(1) (1989) 87-102.

[6] H. Hotelling, Stability in competition. Economic Journal, 39 (1929), 41-57.

[7] P. Jehiel, Product differentiation and price collusion. International Journal of Industrial Organization 10(4) (1992) 633-641.

[8] C.-C. Mai and S.-K. Peng, Cooperation vs. competition in a spatial model. Regional Science and Urban Economics 29(4) (1999) 463-472.

[9] T. Matsumura and N. Matsushima, Cost differentials and mixed strategy equilibria in a Hotelling model. Annals of Regional Science, forthcoming, available at http://dx.doi.org/10.1007/s00168-007-0197-4

[10] K. P. Rath and G. Zhao, Nonminimal product differentiation as a bargaining outcome. Games and Economic Behavior 42(2) (2003) 267-280. 